failure and may be assessed using an appropriate assay for parathyroid hormone. Apparently changes in amino terminal parathyroid hormone provide a more reliable and sensitive indicator of acute parathyroid suppressibility than do changes in carboxy terminal parathyroid hormone.

Identifying patients with non-suppressible parathyroid glands is of considerable clinical importance, since it is these patients who are likely to benefit most from total or subtotal parathyroidectomy. Comparing responsiveness of amino terminal parathyroid hormone to calcium infusion and percentage fall in concentration of the hormone after treatment with $1,25(\mathrm{OH})_{2} \mathrm{D}_{3}$ helps to provide an answer, since there was a significant correlation between percentage suppression of amino terminal parathyroid hormone during calcium infusion and percentage fall in amino terminal parathyroid hormone after prolonged administration of $1,25(\mathrm{OH})_{2} \mathrm{D}_{3}$. These data indicate that patients with less than $30 \%$ suppression of amino terminal parathyroid hormone during calcium infusion will fail to respond to $1,25(\mathrm{OH})_{2}$ $\mathrm{D}_{3}$. The close relation between fall in amino terminal parathyroid hormone during calcium infusion and basal serum calcium concentration suggests that it may be possible to identify those patients likely to respond to $1,25(\mathrm{OH})_{2} \mathrm{D}_{3}$ simply from their serum calcium concentrations, thus obviating the need for infusion. Nevertheless, although this may prove valid for patients with severe hypercalcaemia $(>3.0 \mathrm{mmol} / 1 ;>12.0 \mathrm{mg} / 100 \mathrm{ml}$ ), the response to calcium infusion indicates that patients with mild hypercalcaemia $(2 \cdot 6-3.0 \mathrm{mmol} / 1 ; 10 \cdot 4-12 \cdot 0 \mathrm{mg} / 100 \mathrm{ml})$ may still respond favourably to $1,25(\mathrm{OH})_{2} \mathrm{D}_{3}$. Thus preliminary infusion of calcium may be of value in predicting which patients will respond to long term treatment with $1,25(\mathrm{OH})_{2} \mathrm{D}_{3}$ and which patients would benefit most from early parathyroidectomy.

The research reported in this paper was supported by grants from the Medical Research Council and the National Kidney Research Fund.

\section{References}

1 Slatopolsky E, Rutherford WE, Hoffstein PE, Elkan IO, Butcher HR, Bricker NS. Non-suppressible secondary hyperparathyroidism in chronic progressive renal disease. Kidney Int 1972;1:38-46.

${ }^{2}$ Somerville PJ, Tiller DJ, Evans RA. What is tertiary hyperparathyroidism ? Aust NZ F Med 1975;5:551-6.

${ }^{3}$ Coburn JW, Brickman AS, Sherrard DJ, et al. Use of 1,25-(OH) vitamin $\mathrm{D}_{3}$ to separate "types" of renal osteodystrophy. Proc Eur Dial Transplant Assoc 1977;14:442-50.

${ }^{4}$ Vosik WM, Anderson CF, Steffee WP, Johnson WJ, Arnaud CD, Goldsmith RS. Successful medical management of osteitis fibrosa due to "tertiary" hyperparathyroidism. Mayo Clin Proc 1972;47:110-3.

5 Johnson WJ, Goldsmith RS, Beabout RW, Jowsey J, Kelly PJ, Arnaud $\mathrm{CD}$. Prevention and reversal of progressive secondary hyperparathyroidism in patients maintained by hemodialysis. $\mathrm{Am} \mathcal{J}$ Med 1974;56 827-32.

${ }^{6}$ Adami S, Muirhead N, Manning RM, et al. Control of secretion of parathyroid hormone in secondary hyperparathyroidism. Clin Endocrinol (Oxf) 1982;16:463-73.

${ }^{7}$ Muirhead N, Adami S, Sandler LM, et al. Long-term effects of 1,25dihydroxy vitamin $\mathrm{D}_{3}$ in renal osteodystrophy. $Q 7$ Med 1982:51:424-7.

${ }^{8}$ Goldstein DA, Malluche HH, Massry SG. Management of renal osteodystrophy with $1,25-(\mathrm{OH})_{2} \mathrm{D}_{3}$. 1. Effects of clinical, radiographic and biochemical parameters. Mineral and Electrolyte Metabolism 1979;2: 35-47.

9 Coburn JW, Birdeman AS, Sherrard DJ, et al. Clinical efficacy of 1,25 dihydroxy-vitamin $D_{3}$ in renal osteodystrophy. In: Norman AW, Schaefer K, Coburn JW, et al. Vitamin D, biochemical, chemical and clinical aspects related to calcium metabolism. Berlin: De Gruyter, 1977: 657.

${ }^{10}$ Papapoulos SE, Manning RM, Hendy GN, Lewin IG, O'Riordan JLH. Studies of circulating parathyroid hormone in man using a homologous amino-terminal specific immunoradiometric assay. Clin Endocrinol (Oxf) 1980;13:57-67.

"Manning RM, Hendy GN, Papapoulos SE, O'Riordan JLH. Development of homologous immunological assays for human parathyroid hormone. f Endocrinol 1980;85:161-70.

${ }^{12}$ Martin K, Hruska KA, Freitag JJ, Klahr S, Slatopolsky E. The peripheral metabolism of parathyroid hormone. $N$ Engl f Med 1979;301:1092-8.

${ }^{13}$ Gittes RF, Radde I. Experimental hyperparathyroidism from multiple isologous parathyroid transplants. Endocrinology 1966;78:1015-22.

(Accepted 16 November 1983)

\title{
Diabetic ketoacidosis does not precipitate haemolysis in patients with the Mediterranean variant of glucose-6-phosphate dehydrogenase deficiency
}

\author{
ODED SHALEV, ARIE WOLLNER, JACOB MENCZEL
}

\begin{abstract}
Diabetic ketoacidosis is traditionally stated as being capable of precipitating haemolysis in patients deficient in glucose-6-phosphate dehydrogenase (G6PD). This, however, is based on only a few case reports with inadequate documentation. A study was therefore conducted to review the subject in people with the Mediterranean variant of G6PD deficiency.

Perusal of the medical records for the years 1970-82 yielded 15 patients with G6PD deficiency who had been
\end{abstract}

\footnotetext{
Department of Medicine, Hadassah University Hospital, Mount Scopus, PO Box 24035, Jerusalem 91240, Israel

ODED SHALEV; $M D$, lecturer in internal medicine

ARIE WOLLNER, MD, registrar in internal medicine

JACOB MENCZEL, MD, professor of internal medicine

Correspondence to: Dr Oded Shalev.
}

admitted to hospital for a total of 36 episodes of diabetic ketoacidosis. Ten of these episodes had been complicated by haemolytic anaemia, but in every one there was unequivocal evidence of either concurrent bacterial infection or inadvertent ingestion of drugs, either of which might induce haemolysis in G6PD deficient patients. In the remaining 26 episodes there was no evidence of developing or established haemolytic anaemia.

From these findings diabetic ketoacidosis should not be regarded as a risk factor for haemolysis in the Mediterranean variant of G6PD deficiency.

\section{Introduction}

Textbooks state that diabetic ketoacidosis may precipitate haemolysis in patients with glucose-6-phosphate dehydrogenase (G6PD) deficiency. ${ }^{1}$ This, however, is based on only a few recorded cases, in which the documentation was inadequate. 
The first of these reports ${ }^{2}$ described three black patients who developed an acute, self limiting haemolytic anaemia in association with diabetic ketoacidosis. In only two patients was the diagnosis of G6PD deficiency verified, and in none was information on drugs presented. A subsequent study ${ }^{3}$ reported a black woman who had had 22 episodes of diabetic ketoacidosis, eight of which had been complicated by haemolytic anaemia apparently unrelated to drugs or concurrent infection. The only other association was in a black child who developed haemolytic anaemia nine days after admission for diabetic ketoacidosis, at which time he was already normoglycaemic. ${ }^{4}$ No information was presented to disprove the simultaneous occurrence of infection that conceivably might have precipitated both the haemolytic episode and the ketoacidosis.

In view of the paucity of information we decided to reassess the proposition that diabetic ketoacidosis induces haemolytic anaemia in patients with G6PD deficiency.

\section{Patients, methods, and results}

We reviewed the medical records of patients with the Mediterranean variant of G6PD deficiency who had been admitted to hospital for at least one episode of diabetic ketoacidosis during 1970 to 1982. In all cases G6PD deficiency had been verified by standard screening tests and in 12 by direct enzyme assay. The diagnosis of diabetic ketoacidosis was based on the presence of hyperglycaemia, glycosuria, ketonuria, and arterial $\mathrm{pH}$ less than $7 \cdot 34$. Haemolytic anaemia was determined by a fall in haemoglobin concentration and packed cell volume, an increase in the reticulocyte count, and hyperbilirubinaemia.

There were 15 such patients who had had a total of 36 episodes of diabetic ketoacidosis. Ten of these episodes had been complicated by haemolytic anaemia, but in every one there was unequivocal evidence of either concurrent bacterial infection or inadvertent ingestion of haemolytic drugs, or both. The haemolytic events were characterised by a mean fall in haemoglobin concentration of $4 \cdot 1 \mathrm{~g} / \mathrm{dl}$ (range $1.5-7.4 \mathrm{~g} / \mathrm{dl})$, a mean increase in bilirubin concentration of $58.1 \mu \mathrm{mol} / \mathrm{l}$ $(3.4 \mathrm{mg} / 100 \mathrm{ml}$ ) (range $27 \cdot 4-183.0 \mu \mathrm{mol} / 1 ; 1 \cdot 6-10 \cdot 7 \mathrm{mg} / 100 \mathrm{ml})$, and a mean increase in reticulocytes of $6 \%$ (range $2-12 \%$ ). There was no evidence of haemolysis in the remaining 26 episodes of diabetic ketoacidosis. Most of these had resulted from inadequate insulin treatment.

\section{Discussion}

The results argue against the contention that diabetic ketoacidosis by itself is capable of precipitating haemolysis in patients with the Mediterranean variant of G6PD deficiency.
The conclusion is substantiated by the fact that in 26 of the 36 episodes of diabetic ketoacidosis in the 15 patients reviewed there was no evidence of either developing or established haemolytic anaemia. The 10 episodes of acute haemolytic anaemia which did complicate diabetic ketoacidosis were precipitated by either concurrent bacterial infection or inadvertent ingestion of haemolytic drug(s) or both. Moreover, the presence of diabetic ketoacidosis in itself apparently did not exacerbate the severity of the acute haemolytic episodes, which were mild and self limiting.

The stated role of diabetic ketoacidosis in precipitating haemolysis in G6PD deficiency is based on only six patients. Furthermore, several of the case reports omitted information on drugs ingested and data about possible concurrent infectious diseases, either of which may induce haemolysis in G6PD deficiency. Arguably there are inherent differences between the Mediterranean type of G6PD deficiency and the African type in the six patients previously reported, which may account for different responses to the metabolic derangements in diabetic ketoacidosis. This is unlikely, however, since no laboratory corroboration of increased vulnerability of African type G6PD deficient erythrocytes to oxidant injury was found in in vitro studies in which the cells were exposed to high concentrations of glucose. ${ }^{5}$

We conclude that diabetic ketoacidosis cannot be categorised as a haemolytic factor in the Mediterranean variant of G6PD deficiency. The occurrence of haemolysis in a patient with G6PD deficiency suffering an episode of diabetic ketoacidosis should stimulate a thorough search for possible exposure to an oxidant agent, the existence of an underlying infection, or both.

\section{References}

1 Jacob HS. Hemolysis due to intracorpuscular abnormalities. In: Wyngaarden JB, Smith LH Jr, eds. Cecil textbook of medicine. Philadelphia: W B Saunders Co, 1982:868.

${ }^{2}$ Grant FL, Winks GF. Primaquine sensitive hemolytic anemia complicating diabetic acidosis. Clinical Research Proceedings 1961;9:27.

${ }^{3}$ Burka ER, Weaver Z, Marks PA. Clinical spectrum of hemolytic anemia associated with glucose-6-phosphate dehydrogenase deficiency. Ann Intern Med 1966;64:817-25.

4 Gellady AM, Greenwood RD. G6PDd hemolytic anemia complicating diabetic ketacidosis. F Pediatr 1972;80:1037-8.

5 Glader BE. Role of elevated glucose concentrations in the hemolysis of glucose-6-phosphate dehydrogenase deficient erythrocytes. Proc Soc Exp Biol Med 1975;148:50-3.

(Accepted 3 November 1983)
ONE HUNDRED YEARS AGO Cremation: Apart from sentiment and custom, which, however, in considering a question like this cannot be disregarded, the greatest objection to the adoption of cremation lies in the fact that it might undoubtedly render the detection of murders more difficult. There have been several instances within recen years where murders were only suspected some time after the death and burial of the person murdered, and where unmistakable traces of poison were found when the body was exhumed. Such cases are no doubt the exception, and in the majority of cases of suspected poisoning an inquest has been held and examination of the body made before burial. Where this happens, it would make no difference whether the body was disposed of by cremation or by sepulture, as either way the necessary investigation as to the cause of death takes place first, and where there is reason to suspect foul play, the necessary evidences would in either case be preserved. But where there is no suspicion at the time, and a medical certificate of death has been given in the ordinary course, cremation would undoubtedly remove the means of verifying any suspicions that might subsequently arise, and might prevent murders being detected. Such a possibility is a very serious objection to cremation; and if the practice ever becomes established in this country, it may be necessary to alter our law as to the holding of coroners' inquests, and to insist on them being held in many cases where now they are considered unnecessary. If cremation is to be introduced, it will also be necessary to make laws to regulate it, so as to prevent public feelings being outraged, and to secure proper records being kept. In case of burial, these things are provided for by law, and their observance protected by making those who violate them liable to punishment. As cremation has never been practised in this country, there are no legal regulations applicable to it, except the rule of common law, which forbids it being conducted in such a place or manner as to cause a public nuisance. Mr. Price had selected the top of a mountain for his experiment, and that was held, by the jury, to be a place where no nuisance was created; but a man who burned a body in a populous neighbourhood, unless he did so in a manner different from that observed by Mr. Price, might very possibly be convicted, and if so would be liable to fine and imprisonment, at the direction of the court before which he was convicted. If cremation is to be practised in this country, it should be regulated by law, so as to secure the due observance of public decency, and safety from irregular or premature destruction of the corpse, and to give security from prosecution to those who properly conduct rites which are now seen to be not illegal. (British Medical fournal 1884 ; i:571.) 